\title{
RISK FACTORS OF DEPRESSIVE DISORDER IN PATIENTS WITH TYPE TWO DIABETES MELLITUS- STUDY IN A TERTIARY CARE CENTRE
}

\author{
Lekshmy Gupthan'1, Subha Nanoo², Zinia Thottathil Nujum³, Anil Bindhu4 \\ ${ }^{1}$ Associate Professor, Department of Psychiatry, Government Medical College, Thrissur, Kerala. \\ ${ }^{2}$ Professor (Retired), Department of Psychiatry, Government Medical College, Thiruvananthapuram, Kerala. \\ ${ }^{3}$ Associate Professor, Department of Community Medicine, Government Medical College, Kollam, Kerala. \\ ${ }^{4}$ Professor, Department of Community Medicine, Sree Gokulam Medical College, Venjaramoodu, Thiruvananthapuram, Kerala.
}

\section{BACKGROUND}

ABSTRACT

Depressive disorders are one of the most frequent psychiatric disorders in patients with diabetes mellitus. This is an effort to study the demographic, diabetes related and psychosocial factors associated with depressive disorder in patients with type 2 diabetes mellitus.

\section{MATERIALS AND METHODS}

A hospital-based case control study was conducted in the Diabetic Clinic of a tertiary care hospital in Thiruvananthapuram district of Kerala. 80 cases who were aged $\geq 18$ years were diagnosed to have type 2 diabetes mellitus who have Hospital Anxiety and Depression Scale (HADS)- depression subscale score $\geq 8$ and 80 controls who were the same age group with type 2 diabetes mellitus attending during the same period with HADS depression subscale score less than 8 constituted the study population. Data were collected after taking informed consent. Odds ratio with $95 \%$ confidence interval was calculated. Multivariable analysis was done to find the adjusted odds ratio for factors found to be significant in bivariable analysis.

\section{RESULTS}

The mean age of the cases was $55.14 \pm 8.63$ years and the mean age of controls was $53.13 \pm 10.31$ years. Family history of mental illness, BPL status, longer duration of diabetes, presence of other chronic conditions and higher number of life events and higher mean stress scores were found to be significant risk factors for depression in patients with type 2 diabetes mellitus. Increased social support score was identified as a protective factor.

\section{CONCLUSION}

Certain demographic, diabetes related and psychosocial factors were significantly associated with depression in diabetes mellitus. So it is important to screen diabetic patients with such risk factors for depression, if not all diabetics for resource constraints.

\section{KEYWORDS}

Depression, Risk Factors, Type 2 Diabetes Mellitus, Hospital Anxiety and Depression Scale.

HOW TO CITE THIS ARTICLE: Gupthan L, Nanoo S, Nujum ZT, et al. Risk factors of depressive disorder in patients with type two diabetes mellitus- study in a tertiary care centre. J. Evolution Med. Dent. Sci. 2017;6(89):6167-6171, D0I: $10.14260 /$ jemds/2017/1340

\section{BACKGROUND}

Depression and diabetes are chronic highly prevalent conditions, consuming substantial health care resources. Over the years, researchers have looked into the co-morbidity between these two conditions. A meta-analysis in 2001 concluded that the presence of diabetes doubles the odds of co-morbid depression. ${ }^{1}$ A systematic review in 2012 showed depression nearly twice as high in people with type 2 diabetes compared to those without. $^{2}$ Studies also investigate the biologic and psychosocial factors to explain the interrelationship. Depression is associated with poor glycaemic control, complications of diabetes and psychosocial factors. $3,4,5 \mathrm{~A}$ few studies from India analyse the coexistence of diabetes and depression. A study by Pravin D, Malhotra S et al 'Financial or Other Competing Interest': None.

Submission 26-09-2017, Peer Review 28-10-2017,

Acceptance 03-11-2017, Published 13-11-2017.

Corresponding Author:

Dr. Lekshmy Gupthan,

Associate Professor,

Department of Psychiatry,

Government Medical College, Thrissur.

E-mail: lekshmysiju@gmail.com

DOI: $10.14260 /$ jemds $/ 2017 / 1340$ on the frequency of major affective disorders in first-degree relatives of patients with type 2 diabetes mellitus suggests the increased prevalence of affective disorders in diabetes to non-genetic factors as family aggregation of affective disorders is not demonstrable in type 2 DM. ${ }^{6}$

This study is an effort to identify the demographic, diabetes related and psychosocial risk factors of depressive disorders in type 2 diabetic patients in a tertiary care Hospital in Thiruvananthapuram, Kerala, India.

\section{MATERIALS AND METHODS}

A case control study was conducted in the Diabetic Clinic of Government Medical College, Thiruvananthapuram, Kerala. Cases were individuals aged 18 yrs. or more with type 2 diabetes mellitus and Hospital Anxiety and Depression Scale (HADS)- depression subscale score more than or equal to 8 . Controls were same age group with type 2 diabetes mellitus attending during the same period with HADS depression subscale score less than 8 . Mentally retarded patients were excluded. Sample size was calculated using the StatCalc of Epi Info. Prevalence of exposure among controls was taken as 20 and odds ratio as 3.80 cases and 80 controls were included. Study was conducted after approval from the Ethical Committee (C03/EC03/08/MCT dated 17/04/2008). Written 
informed consent in regional language was obtained from those satisfying the eligibility criteria.

Baseline socio-demographic data; past h/o mental illness; family h/o mental illness, suicide, ADS; alcohol abuse/ dependence; other substance abuse/dependence; duration of diabetes; symptoms of diabetic neuropathy, sexual dysfunction and treatment expenditure were collected from participants. Data on renal/retinal/macrovascular complications, hypertension, other chronic physical conditions, treatment details and HbA1c were collected from medical records.

Hospital Anxiety and Depression Scale is a selfassessment scale, which attempts to measure anxiety and depression without confounding by somatic symptoms of physical disorder. Malayalam version of the HADS has been validated among cancer patients by Pandey et al. ${ }^{7}$ Internal consistency as measured by Cronbach's coefficient alpha is $0.82-0.90$ for HADS-Depression subscale. The HADS-D had by optimal cut-off $>$ or $=8$, sensitivity of 0.80 and specificity of 0.88 and AUC of 0.93 as shown by Olsson I et al. ${ }^{8}$

Presumptive Stressful Life Events Scale (PSLE) was used to measure the number of life events subjects experienced during the past one year and mean stress scores. It was constructed to suit the Indian population and consists of 51 items. ${ }^{9}$

Malayalam translated version of the Berlin Social Support Scale of perceived available support is used in this study. Berlin Social Support Scale was designed by Ralf Schwarzer and Ute Schulz. ${ }^{10}$ This includes 5 psychometric scales- 1 . Perceived Available Support, 2. Need for Support, 3. Support Seeking, 4. Provided support and 5. Actually Received Support. Scale of perceived available support is used in this study. It has 2 components, Emotional and Instrumental. Patients rate their agreement with the statements in the scale on a 4-point basis, strongly disagree (1), somewhat disagree (2), somewhat agree (3) and strongly agree (4).

Statistical Package for Social Sciences (SPSS) version 11 was used to analyse the data. Quantitative variables are summarised using means and standard deviation and qualitative variables using percentages. During the bivariable analysis, qualitative variables were tested for significance using chi-square test and quantitative variables using t-test. Multivariable analysis was done using logistic regression. Crude and adjusted odds ratio with $95 \%$ confidence interval were calculated. $\mathrm{P}$ value of $<0.05$ was considered statistically significant.

\section{RESULTS}

The mean age of controls is $53.13 \pm 10.3$ years and for cases is $55.14 \pm 8.6$ years $(p=0.183)$. The cases and controls were comparable in age. There were 49 males and 111 females in the study.

The following socio-demographic factors were found to be statistically significant in bivariable analysis. Being single (OR 3.14 95\% CI= 1.43 - 6.97), unemployed (OR 2.20, 95\% C.I $1.10-4.42$ ), BPL status (OR 3.85, 95\% CI $1.90-7.85$ ) and family history of mental illness (OR 3.25, 95\% C.I=1.19 - 9.18) (Table 1).

The diabetes related factors found statistically significant in bivariable analysis were duration of diabetes mellitus ( $t$ 3.235, df 158, p 0.001), any diabetic complication (OR 2.54, 95\% C.I= 1.15 - 5.68), diabetic neuropathy (OR 2.30, 95\% C.I= 1.15 - 4.59), stroke (Chi-square value= 7.32, p 0.006), hypertension (OR 2.15, 95\% C.I= 1.09 - 4.26), other chronic physical illness (OR 2.68, 95\% C.I= 1.21 - 5.98) uncontrolled diabetes as per HbA1c values (Chi-square 11.81, p < 0.0005) and treatment with insulin (OR 2.40, 95\% C.I= $1.12-5.20$ ) (Table 2).

On evaluating the psychosocial factors, higher number of life events and higher mean stress scores in past one year were significantly associated with depression. Increased social support emerged as a protective factor (Table 3, 4, 5).

After multivariable analysis, the following factors remained significant as risk factors: The economic status of being below poverty line status, family history of mental illness, longer duration of diabetes and treatment with insulin, presence of other chronic illnesses, higher number of life events and mean stress scores in the past one year (Table $6)$.

\section{RESULTS}

\begin{tabular}{|c|c|c|c|}
\hline Variable & Controls & Cases & P-value \\
\hline SEX & $27(33.8 \%)$ & $22(27.5 \%)$ & Chi-square 0.735, df 1, p 0.391 \\
Male & $53(66.3 \%)$ & $58(72.5 \%)$ & \\
Female & $67(83.8 \%)$ & $48(60 \%)$ & Chi-square 9.89, df 1, p 0.001 \\
\hline MARITAL STATUS & $13(16.2 \%)$ & $32(40 \%)$ & \\
Married & $61(76.2 \%)$ & $58(72.4 \%)$ & Chi-square 2.274, df 3, p 0.518 \\
Single & $11(13.8 \%)$ & $11(13.8 \%)$ & \\
\hline RELIGION & $8(10.0 \%)$ & $11(13.8 \%)$ & \\
Hindu & $6(7.5 \%)$ & $7(8.75 \%)$ & \\
Christian & $12(15 \%)$ & $22(27.5 \%)$ & \\
Muslim & $13(16.25 \%)$ & $18(22.5 \%)$ & Chi-square 7.437, df 6, p 0.732 \\
\hline EDUCATION & $36(45 \%)$ & $26(32.5 \%)$ & \\
Illiterate & $6(7.5 \%)$ & $3(3.75 \%)$ & \\
Primary & $6(7.5 \%)$ & $3(3.75 \%)$ & \\
Middle School & & \\
High School & & \\
Intermediate & & \\
Graduate & &
\end{tabular}




\begin{tabular}{|c|c|c|c|}
\hline Postgraduate/ Professional & $1(1.25 \%)$ & $1(1.25 \%)$ & \\
\hline OCCUPATION & & & \multirow{3}{*}{$\begin{array}{c}\text { Chi-square 5.83, df 1, p 0.015, OR } 2.295 \% \text {, C.I } 1.10 \text { - } \\
4.42\end{array}$} \\
\hline Employed & $40(50 \%)$ & $25(31.2 \%)$ & \\
\hline Unemployed & $40(50 \%)$ & $55(68.8 \%)$ & \\
\hline INCOME & & & \multirow{3}{*}{$\begin{array}{l}\text { Chi-square } 16.9 \text {, df } 1 \text {, p value } 0.00 \text {, OR } 3.85,95 \% \text {, C.I } \\
\qquad 1.90-7.85\end{array}$} \\
\hline APL & $53(66.2 \%)$ & $27(33.8 \%)$ & \\
\hline BPL & $27(33.8 \%)$ & $53(66.2 \%)$ & \\
\hline FAMILY TYPE & & & \multirow{3}{*}{$\begin{array}{c}\text { Chi-square 6.04, p 0.0139, OR } 0.44 \text { 95\%, C.I } 0.22 \text { - } \\
0.90\end{array}$} \\
\hline Nuclear & $58(72.5 \%)$ & $43(53.8 \%)$ & \\
\hline Extended/ Joint & $22(27.5 \%)$ & $37(46.2 \%)$ & \\
\hline PAST H/O MENTAL ILLNESS & & & \multirow{3}{*}{ Chi-square 0.754 , df $1, \mathrm{p} 0.385$} \\
\hline Yes & $5(6.2 \%)$ & $8(10 \%)$ & \\
\hline No & $75(93.8 \%)$ & $72(90 \%)$ & \\
\hline H/O ALCOHOL & \multirow{4}{*}{$\begin{array}{c}5(6.2 \%) \\
75(93.8 \%)\end{array}$} & & \multirow{4}{*}{ Chi-square 0.12 , df $1, \mathrm{p} 0.73$} \\
\hline ABUSE/DEPENDENCE & & & \\
\hline Yes & & $76(9550)$ & \\
\hline No & & $16(95.5 \%)$ & \\
\hline \multicolumn{4}{|c|}{ Table 1. Socio-Demographic Factors } \\
\hline
\end{tabular}

\begin{tabular}{|c|c|c|c|}
\hline Variable & Control & Case & Significance \\
\hline Duration of Diabetes & $7.24 \pm 6.3$ years & $11.07 \pm 8.4$ years & t 3.235, df 158, p 0.001 \\
\hline \multicolumn{4}{|l|}{$\begin{array}{l}\text { Presence of any Diabetic } \\
\text { Complication }\end{array}$} \\
\hline Yes & $52(65 \%)$ & $66(82.5 \%)$ & \multirow{2}{*}{$\begin{array}{c}\text { Chi-square } 6.33 \text {, df } 1 \text {, p } 0.011 \text {, } \\
\text { OR } 2.5495 \% \text {, C.I } 1.15 \text { - } 5.68\end{array}$} \\
\hline No & $28(35 \%)$ & $14(17.5 \%)$ & \\
\hline \multicolumn{4}{|l|}{ Diabetic Neuropathy } \\
\hline Yes & $38(47.5 \%)$ & $54(67.5 \%)$ & \multirow{2}{*}{$\begin{array}{c}\text { Chi-square } 6.55 \text {, df } 1, \mathrm{p} 0.0105 \\
\text { OR } 2.3095 \% \text {, C.I } 1.15 \text { - } 4.59\end{array}$} \\
\hline No & $42(52.5 \%)$ & $26(32.5 \%)$ & \\
\hline \multicolumn{4}{|l|}{ Stroke } \\
\hline Yes & 0 & $7(4.4 \%)$ & \multirow{2}{*}{ Chi-square 7.32, p 0.006} \\
\hline No & $80(100 \%)$ & $73(91.3 \%)$ & \\
\hline \multicolumn{4}{|l|}{ Hypertension } \\
\hline Yes & $29(36.2 \%)$ & $44(55 \%)$ & \multirow{2}{*}{$\begin{array}{c}\text { Chi-square } 5.67 \text {, df } 1, \mathrm{p} 0.0172, \\
\text { OR } 2.1595 \% \text {, C.I } 1.09-4.26\end{array}$} \\
\hline No & $51(63.8 \%)$ & $36(45 \%)$ & \\
\hline \multicolumn{4}{|l|}{$\begin{array}{l}\text { Other Chronic Physical } \\
\text { Conditions }\end{array}$} \\
\hline Yes & $14(17.5 \%)$ & $29(36.2 \%)$ & \multirow{2}{*}{$\begin{array}{c}\text { Chi-square 7.16, df 1, p 0.007, } \\
\text { OR 2.68 95\%, C.I } 1.21 \text { - } 5.98\end{array}$} \\
\hline No & $66(82.5 \%)$ & $51(63.8 \%)$ & \\
\hline \multicolumn{4}{|l|}{ Glycaemic Control } \\
\hline HBA1C $<7 \%$ & $80(100 \%)$ & $69(86.2 \%)$ & \multirow{2}{*}{ Chi-square $11.81, \mathrm{p}<0.0005$} \\
\hline HBA $1 \mathrm{C}>7 \%$ & 0 & $11(13.8 \%)$ & \\
\hline \multicolumn{4}{|l|}{ Treatment with Insulin } \\
\hline Yes & $64(80 \%)$ & $50(62.5 \%)$ & Chi-square 5.98, p 0.014, OR 2.4 \\
\hline No & $16(20 \%)$ & $30(37.5 \%)$ & 95\%, C.I $1.12-5.20$ \\
\hline \multicolumn{4}{|c|}{ Table 2. Diabetes Related Factors } \\
\hline
\end{tabular}

\begin{tabular}{|c|c|c|}
\hline $\begin{array}{c}\text { PSLE- No. of Events in } \\
\text { Past One Year }\end{array}$ & Control & Case \\
\hline Nil & 15 & 5 \\
\hline One event & 34 & 17 \\
\hline Two events & 19 & 27 \\
\hline Three events & 10 & 23 \\
\hline Four events & 2 & 6 \\
\hline Five events & - & 2 \\
\hline \multicolumn{2}{|c|}{ Chi-square value= 21.179, df 5, p= 0.001 } \\
\hline \multicolumn{2}{|c|}{ Table 3. Psychosocial Factors } \\
\hline
\end{tabular}

\begin{tabular}{|c|c|c|}
\hline PSLE Score & Control & Cases \\
Mean & 76.65 & 122.25 \\
SD & 62.77 & 67.98 \\
\hline PSSS-Emotional & 14.46 & 11.15 \\
SD & 1.98 & 4.1 \\
\hline Mean & 13.69 & 10.09 \\
SD & 2.9 & 4.4 \\
\hline \multicolumn{2}{|c|}{ Determinants } \\
\hline \multicolumn{2}{|c|}{} \\
\hline \multicolumn{2}{|c|}{ Table 4. Comparison of Scores of Psychosocial } \\
\hline \multirow{2}{*}{}
\end{tabular}




\begin{tabular}{|c|c|c|c|}
\hline \multirow{2}{*}{ Scores } & \multicolumn{2}{|c|}{ Significance } \\
\cline { 2 - 4 } & Control & Case & $<0.001$ \\
\hline PSSS Emotional & 99.25 & 61.75 & $<0.001$ \\
\hline PSSS Instrumental & 99.07 & 61.92 & $<0.001$ \\
\hline PSLE & 63.34 & 97.66 & \\
\hline \multicolumn{2}{|c|}{ Table 5. Test of Significance of Psychosocial Determinants } \\
\hline
\end{tabular}

\begin{tabular}{|c|c|c|c|c|c|}
\hline Variables & $\beta$ & $\pm \mathrm{SE}$ & $\mathbf{p}$ & Adjusted Odds Rati & 95\% C.I \\
\hline Marital status & 0.989 & 0.512 & 0.054 & 2.687 & $0.984-7.336$ \\
\hline Income & 1.308 & 0.528 & 0.013 & 3.697 & $1.315-10.399$ \\
\hline Family type & 0.616 & 1.095 & 0.574 & 0.540 & $0.063-4.621$ \\
\hline Occupation & 0.128 & 0.642 & 0.842 & 1.137 & $0.323-4.00$ \\
\hline Family h/o mental illness & 1.513 & 0.611 & 0.013 & 4.541 & $1.37-15.0$ \\
\hline Duration of diabetes & 0.082 & 0.035 & 0.02 & 1.086 & $1.013-1.164$ \\
\hline Any complication & 0.315 & 0.515 & 0.541 & 1.371 & $0.499-3.764$ \\
\hline Diabetic neuropathy & 0.375 & 0.597 & 0.688 & 0.530 & $0.213-2.216$ \\
\hline Hypertension & 0.074 & 0.437 & 0.865 & 1.077 & $0.458-2.534$ \\
\hline Other chronic illness & 0.986 & 0.375 & 0.009 & 2.680 & $1.285-5.590$ \\
\hline PSLE no. of events & 1.106 & 0.379 & 3.021 & 0.004 & $1.436-6.356$ \\
\hline \multicolumn{6}{|c|}{ Table 6. Logistic Regression Analysis } \\
\hline
\end{tabular}

\section{DISCUSSION}

The present study identifies socio-demographic factors like the state of being single belonging to a nuclear family and being unemployed; to be significantly associated with depression in type 2 diabetes mellitus. When there is a lack of confiding relationship and lack of support from the spouse or other family members, the burden of coping with the demands of managing a chronic physical illness like diabetes mellitus increases. This in turn contributes to the risk of developing depression.

The economic status of being below poverty line is a socio-demographic factor, which remained significant after multivariable analysis. Low socio-economic status is generally associated with higher physical and psychiatric morbidity and disability partly due to the poorer access to health care. Diabetes mellitus is one of those physical conditions which require regular careful monitoring, frequent visits to health care facilities, lifelong medications and dietary as well as lifestyle modifications. Belonging to a low economic status interferes with all these aspects. ${ }^{11}$

The other socio-demographic factor, which remained significant after multivariable analysis was a family history of mental illness. The physical and emotional stress associated with diabetes mellitus and its management can bring out the lifetime vulnerability to depression imparted by a person's family history. ${ }^{6}$

When the study analysed the diabetes related factors contributing to depression, longer duration of diabetes mellitus and the presence of other chronic illnesses were found as risk factors for depression in diabetes mellitus. As the duration of diabetes mellitus increases, the physical, emotional as well as economical stress of managing the condition increases. There is an increased risk to develop complications including vascular changes in the brain as well, which also contribute to the increased risk of developing depression.

Having more than one chronic physical conditions increases physical disability, which in turn can lead to a decline in productivity and finances. Previous studies by Fisher et al and Ronny Bell et al have shown that presence of chronic physical conditions in diabetes mellitus increases the likelihood of depression. ${ }^{11,12}$ In Indian context, a study on coping with illness has shown that chronic illnesses cause disruption in family and social life due to the associated repetitive psychological distress. ${ }^{13}$

The presence of any diabetic complication was significantly associated with depression in bivariable analysis, but not in multivariable analysis. Among the diabetic complications, diabetic neuropathy and stroke were found to have a significant association with depression. Diabetic neuropathy is a painful condition and it can lead to associated secondary anxiety and depressive symptoms. Cerebrovascular disease has been identified as a causal as well as vulnerability factor in late onset depression. The associated high risk for cerebrovascular disease in diabetes mellitus may explain the high rate of depression in older adults with diabetes. In a study conducted by Poongothai S et al, the complications of diabetes mellitus like retinopathy, neuropathy, nephropathy and peripheral vascular disease were associated with depression even after adjusting for age, gender, duration of diabetes and glycated haemoglobin. ${ }^{14}$ Bruce DG et al, in a study found that a positive history of stroke is significantly associated with depression. ${ }^{15}$

A population based study by Li C, Ford ES et al showed that people with type 2 diabetes mellitus who were currently using insulin had a higher rate of depression than who were not, similar to the finding in this study. ${ }^{16}$ So more careful psychological support is needed to patients who are receiving treatment with insulin.

Moving on to the psychosocial factors, the study found that there was significantly higher number of life events in the past one year in depressed diabetic patients. Mean stress score in past one year was also significantly higher in them. The life events in depressed diabetic patients were mostly undesirable events (unemployment, financial problems, major personal illness, marital conflict, death of spouse, etc.). Both the variables, number of life events in the past one year and mean stress score remained significant after the logistic regression analysis also. 
So there is a role of negative life events in developing depression in diabetes mellitus indicating that depression in diabetes is not due to disease burden alone. Many life stresses together with diabetes combine to produce depression in diabetes.

This study identifies increased social support (PSSS: emotional and instrumental) as a protective factor. When an individual is coping with a chronic illness, social network interactions are a potential source of support. Support given by the family as well as other caregivers around the patient is an important factor protecting from the stress of the disease. A cross-sectional observational study among rural AfricanAmericans to examine the correlates of elevated depressive symptoms in type 2 diabetes mellitus showed community support and social support to be significantly associated with depression as the present study. ${ }^{12}$ Hence, we can conclude that there is an interaction of biological, environmental and psychological factors in the development of depression in diabetes mellitus.

\section{CONCLUSION}

Family history of mental illness, low income, longer duration of diabetes, presence of other chronic conditions and life events in past one year, both number and mean stress scores were found to be risk factors of depression among patients with type 2 diabetes mellitus. Increased social support was identified as a protective factor. Women were over represented in the study sample and this was a limitation in this study.

\section{REFERENCES}

[1] Anderson RJ, Freedland KE, Clouse RE, et al. The prevalence of comorbid depression in adults with diabetes: a meta-analysis. Diabetes Care 2001;24(6):1069-78.

[2] Roy T, Lloyd CE. Epidemiology of depression and diabetes: a systematic review. J Affect Disord 2012;142 Suppl:S8-21.

[3] Lustman PJ, Anderson RJ, Freedland KE, et al. Depression and poor glycemic control: a meta-analytic review of the literature. Diabetes Care 2000;23(7):934-42.

[4] Padgett DK. Sociodemographic and disease-related correlates of depressive morbidity among diabetic patients in Zagreb, Croatia. J Nerv Ment Dis 1993;181(2):123-9.
[5] Lloyd CE, Mathews KA, Wing RR, et al. Psychosocial factors and complications of IDDM: the pittsburgh epidemiology of diabetes complications study. VIII. Diabetes Care 1992;15(2):166-72.

[6] Pravin D, Malhotra S, Chakrabarti S, et al. Frequency of major affective disorders in first degree relatives of patients with type 2 diabetes mellitus. Indian J Med Res 2006;124:291-8.

[7] Thomas BC, Devi N, Sarita GP, et al. Reliability and validity of the Malayalam hospital anxiety and depression scale (HADS) in cancer patients. Indian J Med Res 2005;122(5):395-9.

[8] Olsson I, Mykletun A, Dahl AA. The hospital anxiety and depression rating scale: a cross sectional study of the psychometrics and case finding abilities in general practice. BMC Psychiatry 2005;5:46.

[9] Singh G, Kaur D, Kaur H. Presumptive stressful life events scale-a new stressful life events scale for use in India. Indian J Psychiatry 1984;26(2):107-14.

[10] Schulz U, Schwarzer R. Social support in coping with illness: the berlin social support scales. Diagnostica 2003;49:73-82.

[11] Brown AF, Ettner SL, Piette J, et al. Socioeconomic position and health among persons with diabetes mellitus-a conceptual framework and review of literature. Epidemiol Rev 2004;26:63-77.

[12] Fisher L, Chesla CA, Mullan JT, et al. Contributors to depression in Latino and European-American patients with type 2 diabetes mellitus. Diabetes Care 2001;24(10):1751-7.

[13] Soneja S, Nagarkar KM, Dey AB. Indian elderly: coping with chronic illness. Journal of Hong Kong Geriatric Society 1999;9:10-3.

[14] Poongothai S, Anjana RM, Pradeepa R, et al. Association of depression with complications of type 2 diabetes--the Chennai urban rural epidemiology study (CURES- 102). J Assoc Physicians India 2011;59:644-8.

[15] Bruce DG, Casey G, Davis WA, et al. Vascular depression in older people with diabetes. Diabetologia 2006;49(12):2828-36.

[16] Li C, Ford ES, Strine TW, et al. Prevalence of depression among U.S adults with diabetes findings from the 2006 behavioral risk factor surveillance system. Diabetes Care 2008;31(1):105-7. 